\title{
Neuroprotective Function of DJ-1 in Parkinson's Disease
}

\author{
Hiroyoshi Ariga, ${ }^{1}$ Kazuko Takahashi-Niki, ${ }^{1}$ Izumi Kato, ${ }^{1}$ Hiroshi Maita, ${ }^{1}$ \\ Takeshi Niki, ${ }^{2}$ and Sanae M. M. Iguchi-Ariga ${ }^{2}$ \\ ${ }^{1}$ Graduate School of Pharmaceutical Sciences, Hokkaido University, Kita-ku, Sapporo 060-0812, Japan \\ ${ }^{2}$ Graduate School of Agriculture, Hokkaido University, Kita-ku, Sapporo 060-8589, Japan \\ Correspondence should be addressed to Hiroyoshi Ariga; hiro@pharm.hokudai.ac.jp
}

Received 29 March 2013; Revised 24 April 2013; Accepted 29 April 2013

Academic Editor: Anne-Laure Bulteau

Copyright (C) 2013 Hiroyoshi Ariga et al. This is an open access article distributed under the Creative Commons Attribution License, which permits unrestricted use, distribution, and reproduction in any medium, provided the original work is properly cited.

\begin{abstract}
Parkinson's disease (PD) is caused by dopaminergic neuronal death in the substantia nigra, resulting in a reduced level of dopamine in the striatum. Oxidative stress and mitochondrial dysfunction are thought to be major causes of neurodegeneration in PD. Although genetic and environmental factors are thought to affect the onset of PD, precise mechanisms at the molecular level have not been elucidated. The DJ-1 gene is a causative gene for familial PD (park7) and also an oncogene. DJ-1 has various functions, including transcriptional regulation, antioxidative stress reaction, and chaperone, protease, and mitochondrial regulation, and its activity is regulated by its oxidative status, especially that of cysteine 106 (C106) of DJ-1. Excess oxidation of DJ-1, which renders DJ-1 inactive, has been observed in patients with sporadic PD and Alzheimer's disease, suggesting that DJ-1 also participates in the onset and pathogenesis of sporadic PD as well as familial PD. DJ-1 is also a stress sensor and its expression is increased upon various stresses, including oxidative stress. In this review, we describe functions of DJ-1 against oxidative stress and possible roles of DJ-1 in the pathogenesis of PD.
\end{abstract}

\section{Introduction}

Parkinson's disease $(\mathrm{PD})$ is a progressive neurodegenerative disease that occurs in approximately $1 \%$ of the population over the age of 65 years. There are two types of PD, familial and sporadic forms of PD. Although familial PD cases account for $10 \%$ of total cases of PD, investigations of the functions of familial PD gene products have provided great insights into the molecular mechanisms of the onset of PD, and familial PD gene products are thought to also play roles in the pathogenesis of sporadic PD (see recent reviews $[1,2]$ ).

The DJ-1 gene has been identified by us as a novel oncogene that transforms mouse NIH3T3 cells in cooperation with activated ras in 1997 [3]. In 2003, Bonifati et al. found a large deletion and missense mutation in the $D J-1$ gene in Italian and Dutch PD patients, leading to identification of the DJ-1 gene as a causative gene for familial PD park7 with recessive inheritance [4]. Twenty-three pathogenic deletion and point mutations were found in patients with PD (see Parkinson's disease mutation database and references therein, http://www.molgen.ua.ac.be/PDmutDB/ default.cfm?MT $=0-\& \mathrm{ML}=0 \&$ Page $=$ Home). Compared to parkin and Pinkl, other causative genes of familial PD with recessive inheritance, the number of mutations in the DJ-1 gene is small; numbers of mutations of the three genes are the order of parkin $>$ Pink $1>D J-1$. This might be due to the position of DJ-1 during the course of onset of PD; DJ-1 may be placed upstream of Pinkl and parkin $[1,2]$.

In this review, we describe functions of DJ-1 against oxidative stress and discuss how loss of function of DJ-1 affects the pathogenesis of PD.

\section{Structure, Expression, and Function of DJ-1}

DJ-1 is comprised of 189 amino acids with seven $\beta$-strands and nine $\alpha$-helices in total and is present as a dimer [5-9]. Amino acid sequences of DJ-1 are conserved from prokaryotes to eukaryotes and they are now named DJ-1 superfamily [10]. DJ-1 is structurally most similar to the monomer subunit 


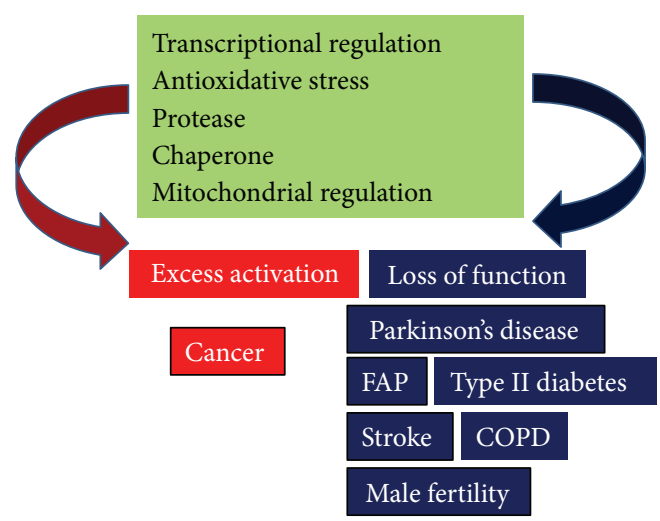

FIGURE 1: Functions of DJ-1 and its related diseases. DJ-1 is a multifunctional protein. It is thought that excess activation and loss of function of DJ-1 trigger the onset of various diseases, including cancer and Parkinson's disease.

of protease I, the intracellular cysteine protease from Pyrococcus horikoshii $[5,11]$. DJ-1, however, contains an additional $\alpha$-helix at the C-terminal region, which blocks the putative catalytic site of DJ-1 [5-7].

DJ-1 is expressed in almost all cells and tissues, including the brain [3]. DJ-1 is expressed in both neurons and glia cells $[4,12,13]$. The expression level of DJ-1 is increased in cells, including reactive astrocytes, under an oxidative stress condition [14], and overexpression of DJ-1 is observed in reactive astrocytes in sporadic PD and other neurodegenerative diseases [12, 15-17]. Knockdown or knockout of DJ-1 expression in astrocytes impairs astrocyte-mediated neuroprotection against oxidative stress through deregulation of mitochondrial complex I and inflammatory responses [17-20].

DJ-1 is a multifunctional protein that participates in transcriptional regulation [21-29], antioxidative stress reaction [14, 30-36], and chaperone [37, 38], protease [39-41], and mitochondrial regulation [33, 42-52] (Figure 1). DJ-1 is located in the cytoplasm, nucleus, and mitochondria in cells, and secreted DJ-1 has been observed in various cultured cells and tissues, including cancer cells and tissues [14, 40, 53-60] and astrocytes [14]. DJ-1 is translocated from the cytoplasm to nucleus upon exposure to growth factors [3], and oxidation of C106 described later is necessary for nuclear translocation of DJ-1 [61]. DJ-1 contains three cysteine residues, C46, C56, and C106. Of the three cysteine residues, C106 is highly susceptible to oxidative stress and is oxidized as $\mathrm{SOH}, \mathrm{SO}_{2} \mathrm{H}$, and then $\mathrm{SO}_{3} \mathrm{H}[30,33,34]$, and mutation of $\mathrm{C} 106$ results in loss of all of DJ-1's functions [32, 33, 35] (Figure 2). DJ-1 at C106 with $\mathrm{SO}_{3} \mathrm{H}$ is thought to be an inactive form of DJ-1 [38], and excessive oxidized DJ-1 has been observed in brains of patients with PD and Alzheimer's disease [15, 62]. DJ-1 thus possesses quenching activity against reactive oxygen species (ROS) by self-oxidation of its cysteine residues [32, 63]. Phylogenetic analyses showed that, of the DJ-1 superfamily from prokaryotic and eukaryotic representatives, C106 is highly conserved and important for their functions, including enzymatic activities such as thiamin biosynthetic enzymes, protease and isocyanide hydratase, chaperone, and stress

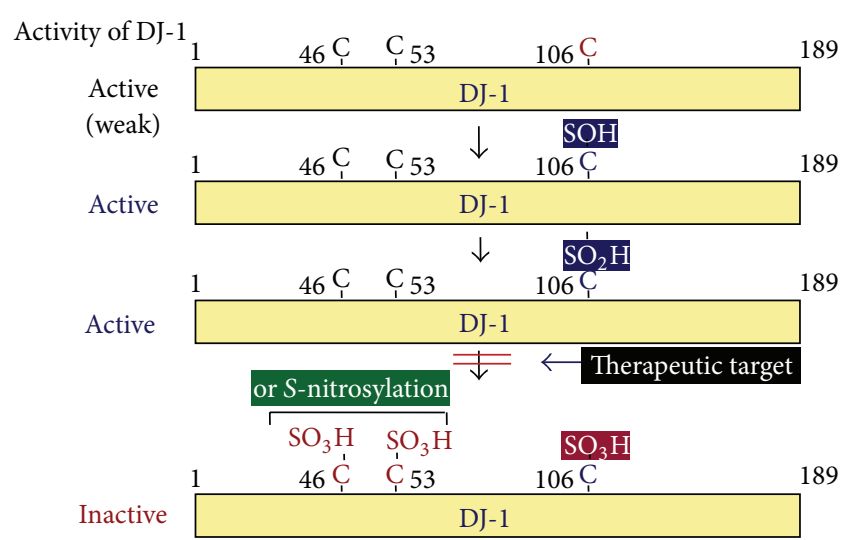

FIGURE 2: Cysteine oxidation and activation of DJ-1. DJ-1 contains three cysteine residues at amino acid numbers 46, 54, and 106 (C46, C54, and C106, resp.). C106 is sequentially oxidized with $\mathrm{SOH}, \mathrm{SO}_{2} \mathrm{H}$, and $\mathrm{SO}_{3} \mathrm{H}$, and then $\mathrm{C} 46$ and $\mathrm{C} 54$ are oxidized or $\mathrm{S}$ nitrosylated.

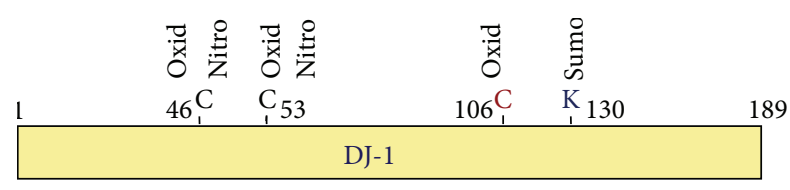

Oxid: Oxidation

Sumo: Sumoylation

Nitro: S-nitrosylation

FIgure 3: Posttranslational modifications on DJ-1. DJ-1 is oxidized at amino acid numbers 46, 54, and 106 (C46, C54, and C106, resp.), $S$-nitrosylated at C46 and C54 and sumoylated at K130.

response ([10, 64], references therein). DJ-1 is also modified by sumoylation [65], S-nitrosylation [66], and phosphorylation [67] (Figure 3). Sumoylation of DJ-1 occurs under an oxidative stress condition in concomitant with acidic shift of DJ-1. Sumoylation of DJ-1 at lysine 130 is necessary for its activity, and excess sumoylation is observed in an L166P pathogenic mutant of DJ-1 [65]. S-nitrosylation is observed at cysteines 46 and 53 of DJ-1 under a nitrosative stress condition and affects dimerization of DJ-1, which is necessary for DJ-1 to exert its function [66]. DJ-1 is also phosphorylated in a p53-dependent manner, but phosphorylated amino $\operatorname{acid}(s)$ and the effect of phosphorylation on DJ-1 function are not known [67]. From these points, it is thought that DJ-1 also participates in the pathogenesis of sporadic PD as well as familial PD.

\section{Transcriptional Regulation of DJ-1 in Response to Oxidative Stress and Dopamine Synthesis}

Although DJ-1 does not directly bind to DJ-1 [68], it regulates the activity of DNA-binding transcription factors as a coactivator or corepressor through binding to DJ-1binding transcription factors. Transcription factors whose 

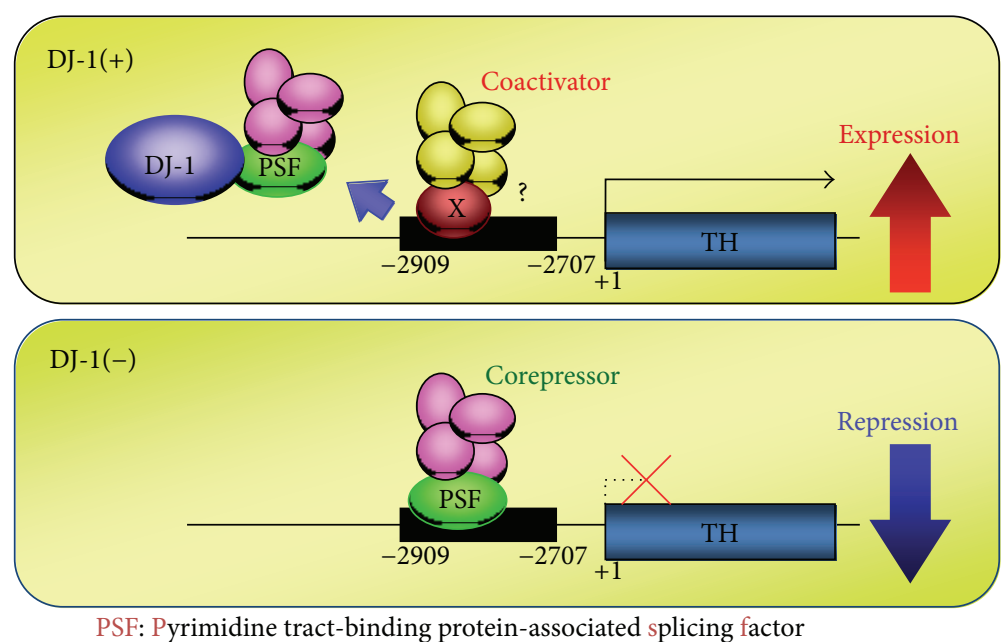

FIGURE 4: Schematic model of activation of the tyrosine hydroxylase gene by DJ-1. In the absence of DJ-1, PSF binds to the promoter region spanning -2909 to -2707 of the tyrosine hydroxylase (TH) gene to repress its transcription. In the presence of DJ-1, DJ-1 binds to PSF to sequester PSF from the TH gene, resulting in replacement of the corepressor complex with a coactivator complex, thereby activating TH gene transcription.

activity is regulated by DJ-1 include the androgen receptor $[21,22,27]$, polypyrimidine tract-binding protein-associated splicing factor (PSF) [25], p53 [23, 28, 69, 70], nuclear factor erythroid-2-related factor 2 (Nrf2) [26], and sterol regulatory element binding protein (SREBP) [68]. Considering oxidative stress response and dopamine synthesis, regulation of $\mathrm{Nrf} 2$, p53, and PSF by DJ-1 is important. Nrf2 is a master transcription factor for oxidative stress and detoxication responses. Without such stresses, Nrf2 is localized in the cytoplasm in a complex with Keap1, resulting in degradation by the ubiquitin-proteasome system. Upon oxidative stress, DJ-1 sequesters Keap1, leading to translocation of Nrf2 into the nucleus to activate various antioxidative stress genes, thereby decreasing the ROS level [26]. p53 is a tumor suppressor and plays roles in induction of senescence and apoptosis in cells and in regulation of mitochondrial homeostasis against oxidative stress. DJ-1 directly binds to p53 and regulates p53 activity in various ways; $\mathrm{p} 53$ is activated by Topors-mediated sumoylation and inactivated by DJ-1 through inhibition of Topors activity [23], and DJ-1 binds to the DNA-binding region of p53 to inhibit p53 transcriptional activity when affinity of p53 or its mutants to DNA is low, leading to cell cycle progression [70]. It has also been reported that DJ1 inhibits the induction of apoptosis by p53-induced Bax expression [69]. DJ-1 stimulates the expression of superoxide dismutase (SOD 3) and glutathione ligase genes by an unknown mechanism to reduce ROS level [71, 72].

Dopamine is synthesized from tyrosine by two enzymes: tyrosine hydroxylase (TH) converts tyrosine to L-DOPA and L-DOPA carboxylase (DDC) converts L-DOPA to dopamine. Dopamine is then packed in synaptic vesicles by vesicular monoamine transporter 2 (VMAT2). Although TH level in PD patients is decreased, it is not changed in DJ-1knockout mice [73-75]. DJ-1 positively regulates human $\mathrm{TH}$ gene expression by sequestering transcriptional repressor PSF from the human TH gene promoter [25] (Figure 4). This

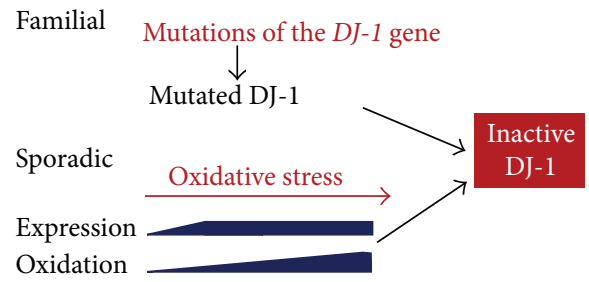

Figure 5: Proposed model of the role of DJ-1 in the onset of Parkinson's disease. In the case of familial Parkinson's disease (PD), the DJ-1 gene is heritably mutated, giving rise to inactive DJ-1 that causes PD. In the case of sporadic PD, DJ-1 expression is induced in cells upon oxidative stress to prevent cell death. During the course of continuous oxidative stress, DJ-1 is highly oxidized, giving rise to inactive DJ-1 that causes PD.

upregulation is only observed in the human $\mathrm{TH}$ gene due to lack of the PSF-recognition sequence in the mouse TH gene, and highly oxidized DJ-1 loses this activity [29]. This finding indicates one of the reasons for no change in $\mathrm{TH}$ level in DJ-1-knockout mice. DJ-1 also regulates enzymatic activities of TH and DDC [76]. When the sum of SH (reduced) and $\mathrm{SOH}$ forms of $\mathrm{C} 106$ is more than $50 \%$ of total forms of $\mathrm{C} 106$, DJ-1 upregulates TH and DDC activities, suggesting that the activity of DJ-1 toward TH and DDC is changed depending on the level of oxidative stress and that it is decreased with aging, which is one of the crucial factors for onset of PD (Figure 5). DJ-1 positively regulates expression of the VMAT2 gene and VMAT2 activity through transcriptional coactivator and protein-protein interaction, respectively [77]. Since VMAT2 re-uptakes excess dopamine into synaptic vesicles to prevent neurons from oxidized dopamine-induced damage, upregulation of VMAT activity by DJ-1 contributes to this reaction. Pathogenic mutations of DJ-1, including both homozygous and heterozygous mutations, have reduced stimulating activity against TH, DDC, and VMAT2 [29, 76, 77]. 


\section{Chaperone and Protease Activity of DJ-1}

Structures of DJ-1, Escherichia coli chaperone Hsp31 and an Archaea protease are conserved [7]. DJ-1 inhibits the aggregation of $\alpha$-synuclein under an oxidative condition by its chaperone activity $[37,38]$. As stated in Section 2 , the structure of DJ-1 is similar to that of cysteine protease from Pyrococcus horikoshii, but C-terminal $\alpha$-helix 9 blocks a catalytic domain of protease [5]. DJ-1 in dopaminergic cells undergoes $\mathrm{C}$-terminal cleavage in response to mild oxidative stress, and a C-terminally cleaved form of DJ-1 with activated protease activity enhances cytoprotective action against oxidative stress-induced apoptosis [41]. Although protease activity is still in debate, low protease activity of DJ-1 has been reported [39-41]. Transthyretin, a causative protein in familial amyloidotic polyneuropathy (FAP), is degraded in cells transfected with full-sized DJ-1 and in vitro by recombinant DJ-1 lacking $\alpha$-helix 9 , and mutation of C106 in DJ-1 results in loss of its protease activity [40]. Localizations of DJ-1 and amyloid plaque of transthyretin in FAP patients are mirror images [40], and faint staining of DJ1 is observed in the outer halo of Lewy bodies in PD patients [15]. These results suggest that $\alpha$-helix 9 of DJ-1 is opened in cells under oxidative stress conditions in which oxidized protein(s) begins to aggregate and that DJ-1 degrades an aggregated protein(s) that causes neurodegenerative diseases. Identification of the recognition sequence of DJ-1 protease and of the protein(s) that opens $\alpha$-helix 9 of DJ-1 in cells will lead to elucidation of the physiological role of DJ-1 protease.

\section{DJ-1-Mediated Signaling Pathways against Oxidative Stress}

There are several pathways against oxidative stress and these pathways prevent cell death, thereby leading to cell growth. The phosphoinositide 3-kinase (PI3 K)/Akt pathway is the major growth signaling pathway. When cells receive growth signals such as epidermal growth factor (EGF) stimulation, PI3 K triggers phosphorylation of Akt/protein kinase B $(\mathrm{PKB})$, leading to activation of continuous phosphorylation cascades, resulting in stimulation of cell growth (see reviews [78, 79] and references therein). Phosphatase and Tensin homolog deleted from chromosome 10 (PTEN) is a lipid phosphatase that inhibits PI3 K and acts as a negative regulator of the PI3 K/Akt pathway. DJ-1 directly binds to PTEN to inhibit its enzymatic activity [80,81]. After oxidative stress such as that caused by injection of a neurotoxin into mice or by addition of a neurotoxin to cultured cells, the Akt pathway is activated concomitantly with inactivation of PTEN in mouse brains and cultured cells, and the phosphorylation level of Akt is reduced in DJ-1-knockout mice, leading to neuronal cell death [80-82].

Apoptosis signal-regulating kinase 1 (ASK1) is mitogenactivated protein kinase-kinase-kinase 5 (MAP3 K5). It activates c-Jun N-terminal kinase (JNK) and p38 mitogenactivated protein kinases in response to various stresses such as oxidative stress, endoplasmic reticulum stress and calcium influx. TNF- $\alpha$, LPS, and ischemia also trigger the generation of ROS, resulting in activation of ASK1 (see reviews [83, 84], references therein). ASK1 has been found to be involved in cancer $[85,86]$, diabetes $[87,88]$, and cardiovascular diseases [88-90] and neurodegenerative diseases [91-93]. These phenomena are similar to those observed in DJ-1mediated diseases [3, 4, 40, 94-99]. The generation of ROS is also crucial for TNF- $\alpha$-induced signaling pathway that leads to apoptosis, and treatment of cells with antioxidants such as $\mathrm{N}$-acetyl-l-cysteine (NAC) inhibits apoptosis induction [83]. Daxx, a death domain-associated protein, associates with ASK1 in the cytoplasm to induce apoptosis after cells are treated with TNF- $\alpha[83,84]$. DJ-1 binds to both Daxx and ASK1 to sequester Daxx into the nucleus, preventing Daxx from association with ASK1, thereby inhibiting oxidative stress-induced apoptosis in $\mathrm{H}_{2} \mathrm{O}_{2}$-treated cultured cells and MPTP-administered-PD model mice [100, 101]. Pathogenic mutants of DJ-1 do not have this activity [102].

The ERK pathway is the main cell-progression pathway starting from Ras, followed by Raf, Mek, and ERK. DJ-1 protects against dopamine toxicity through the Erk kinase pathway in which DJ-1 and Erk are mutually activated upon administration of dopamine into mice or cultured cells [103]. It has been reported that an accelerated loss of substantia nigra cell bodies containing dopamine neurons was observed in aging mice lacking DJ-1 and the glial cell line-derived neurotrophic factor receptor Ret and that DJ-1 interacts with ERK signaling [104]. Furthermore, DJ-1 protects dopaminergic neurons against rotenone-induced apoptosis by enhancing ERK-dependent mitophagy [105]. Thus, DJ-1 prevents cells from oxidative stress-induced death by regulating various signaling pathways.

\section{Role of DJ-1 in Mitochondrial Homeostasis}

Mitochondrial dysfunction, including reduced mitochondrial complex I activity and mitochondrial membrane potential, is observed in PD patients [106-110] and in DJ-1knockout mice and flies $[47,111]$. Fragmented mitochondria are observed in DJ-1-knockout mice and cells [46, 48, 51]. Although a portion of DJ-1 is present in mitochondria under normal conditions $[45,112]$ and DJ-1 binds to subunits of mitochondrial complex I to regulate its activity [45], the translocation of DJ-1 into mitochondria is stimulated by oxidative stress, and oxidation of $\mathrm{Cl06}$ with $\mathrm{SO}_{2} \mathrm{H}$ and $\mathrm{N}$-terminal 12 amino acids is necessary for mitochondrial translocation of DJ-1 $[33,113]$. Pathogenic DJ-1 mutants such as L166P and M26I DJ-1 are localized in mitochondria as monomers [113]. DJ-1 ectopically targeted to mitochondria by the addition of an $\mathrm{N}$-terminal mitochondrial targeting sequence has been shown to be more protective against oxidative stress-induced cell death [44]. Considering these findings, it is thought that localization of DJ-1 as a dimer in mitochondria is required for DJ-1 to play a role in antioxidative stress reaction and that DJ-1 localized in mitochondria as a monomer, such as M26I and L166P DJ-1, is, in contrast, harmful to cells.

DJ-1 has no mitochondria-targeting sequence and binds to several chaperones, including Hsp70, CHIP, and 
mitochondrial Hsp70/mortalin/Grp75, suggesting that translocation of DJ-1 into mitochondria relies on or depends on other proteins, including mortalin [43]. Mortalin plays a central role in mitochondrial homeostasis through its capacity to direct the import of nuclear-encoded proteins carrying an internal mitochondrial targeting sequence into mitochondria, and mutations of the mortalin gene were found in patients with Parkinson's disease [114].

The role of DJ-1 in autophagy is still in debate, and almost all of the reports focused on mitochondria-specific autophagy, mitophagy. When mitochondrial membrane potential is decreased, DJ-1 is translocated into mitochondria to induce mitophagy, which is clearance of damaged mitochondria $[48,50,52]$. DJ-1 seems to act in parallel to the Pink1/Parkin-mediated mitophagy pathway [50]. Although mitochondrial functions of DJ-1 have been extensively studied, the precise mechanism of mitophagy induction by DJ-1 is still poorly understood.

\section{Conclusion and Perspective}

DJ-1 has multiple functions and plays a protective role against oxidative stress-induced cell death by using all of its functions. DJ-1 is also a stress sensor and its expression is increased upon various stresses, including oxidative stress. Loss of function and reduced function of DJ-1 trigger the onset of oxidative stress-related diseases, including Parkinson's disease $[4,94,95]$, stroke $[96,97]$, familial amyloidotic polyneuropathy [40], chronic obstructive pulmonary disease (COPD) [98], and type II diabetes [99]. The oxidative status of C106 of DJ-1 determines all of the functions of DJ-1. Excess oxidation of C106 renders DJ-1 inactive, and highly oxidized DJ-1 has been observed in patients with Parkinson's disease and Alzheimer's disease. These results suggest that block of excessive oxidation of DJ-1 is a therapeutic target for the oxidative stress-related diseases stated earlier. Indeed, DJ-1binding compounds that bind to the C106 region of DJ-1 showed neuroprotective activity against neurodegeneration in Parkinson's disease and stroke animal models through inhibition of excessive oxidation of C106 of DJ-1 [115-117].

$\begin{array}{ll}\text { Abbreviations } \\ \text { PD: } & \text { Parkinson's disease } \\ \text { PSF: } & \begin{array}{l}\text { Polypyrimidine tract-binding } \\ \text { protein-associated splicing factor }\end{array} \\ \text { ROS: } & \text { Reactive oxygen species } \\ \text { Nrf2: } & \text { Nuclear factor erythroid-2 related factor } 2 \\ \text { TH: } & \text { Tyrosine hydroxylase } \\ \text { DDC: } & \text { L-DOPA carboxylase } \\ \text { VMAT2: } & \text { Vesicular monoamine transporter } 2 \\ \text { PTEN: } & \text { Phosphatase and Tensin homolog deleted } \\ & \text { from chromosome } 10 \\ \text { ASK1: } & \text { Apoptosis signal-regulating kinase } 1 .\end{array}$

\section{Conflict of Interests}

The authors declare that they have no financial conflict of interests.

\section{Acknowledgments}

This work was supported by grants-in-aid from the Ministry of Education, Science, Culture and Sports and by the Program for Promotion of Fundamental Studies in Health Science of the National Institute of Biomedical Innovation (NIBIO) in Japan.

\section{References}

[1] D. N. Hauser and T. G. Hastings, "Mitochondrial dysfunction and oxidative stress in Parkinson's disease and monogenic parkinsonism," Neurobiology of Disease, vol. 51, pp. 35-42, 2013.

[2] Y. Sai, Z. Zou, K. Peng, and Z. Dong, "The Parkinson's diseaserelated genes act in mitochondrial homeostasis," Neuroscience \& Biobehavioral Reviews, vol. 36, no. 9, pp. 2034-2043, 2012.

[3] D. Nagakubo, T. Taira, H. Kitaura et al., "DJ-1, a novel oncogene which transforms mouse NIH3T3 cells in cooperation with ras," Biochemical and Biophysical Research Communications, vol. 231, no. 2, pp. 509-513, 1997.

[4] V. Bonifati, P. Rizzu, M. J. van Baren et al., "Mutations in the DJ-1 gene associated with autosomal recessive early-onset parkinsonism," Science, vol. 299, no. 5604, pp. 256-259, 2003.

[5] K. Honbou, N. N. Suzuki, M. Horiuchi et al., "The crystal structure of DJ-1, a protein related to male fertility and Parkinson's disease," The Journal of Biological Chemistry, vol. 278, no. 33, pp. 31380-31384, 2003.

[6] X. Tao and L. Tong, "Crystal structure of human DJ-1, a protein associated with early onset Parkinson's disease," The Journal of Biological Chemistry, vol. 278, no. 33, pp. 31372-31379, 2003.

[7] S. J. Lee, S. J. Kim, I. K. Kim et al., "Crystal structures of human DJ-1 and Escherichia coli Hsp31, which share an evolutionarily conserved domain," The Journal of Biological Chemistry, vol. 278, no. 45, pp. 44552-44559, 2003.

[8] M. A. Wilson, J. L. Collins, Y. Hod, D. Ringe, and G. A. Petsko, "The 1.1- $\AA$ resolution crystal structure of DJ-1, the protein mutated in autosomal recessive early onset Parkinson's disease," Proceedings of the National Academy of Sciences of the United States of America, vol. 100, no. 16, pp. 9256-9261, 2003.

[9] Q. Huai, Y. Sun, H. Wang et al., "Crystal structure of DJ-1/RS and implication on familial Parkinson's disease," The FEBS Letters, vol. 549, no. 1-3, pp. 171-175, 2003.

[10] S. Bandyopadhyay and M. R. Cookson, "Evolutionary and functional relationships within the DJ1 superfamily," $B M C$ Evolutionary Biology, vol. 4, article 6, 2004.

[11] X. Du, I. G. Choi, R. Kim et al., "Crystal structure of an intracellular protease from Pyrococcus horikoshii at 2-Å resolution," Proceedings of the National Academy of Sciences of the United States of America, vol. 97, no. 26, pp. 14079-14084, 2000.

[12] P. Rizzu, D. A. Hinkle, V. Zhukareva et al., "DJ-1 colocalizes with tau inclusions: a link between parkinsonism and dementia," Annals of Neurology, vol. 55, no. 1, pp. 113-118, 2004.

[13] T. Yanagida, K. Takata, M. Inden et al., "Distribution of DJ1, Parkinson's disease-related protein PARK7, and its alteration in 6-hydroxydopamine-treated hemiparkinsonian rat brain," Journal of Pharmacological Sciences, vol. 102, no. 2, pp. 243-247, 2006.

[14] T. Yanagida, J. Tsushima, Y. Kitamura et al., "Oxidative stress induction of DJ-1 protein in reactive astrocytes scavenges free radicals and reduces cell injury," Oxidative Medicine and Cellular Longevity, vol. 2, no. 1, pp. 36-42, 2009. 
[15] R. Bandopadhyay, A. E. Kingsbury, M. R. Cookson et al., "The expression of DJ-1 (PARK7) in normal human CNS and idiopathic Parkinson's disease," Brain, vol. 127, part 2, pp. 420 430, 2004.

[16] M. Neumann, V. Müller, K. Görner, H. A. Kretzschmar, C. Haass, and P. J. Kahle, "Pathological properties of the Parkinson's disease-associated protein DJ-1 in $\alpha$-synucleinopathies and tauopathies: relevance for multiple system atrophy and Pick's disease," Acta Neuropathologica, vol. 107, no. 6, pp. 489496, 2004.

[17] S. J. Mullett, R. L. Hamilton, and D. A. Hinkle, "DJ-1 immunoreactivity in human brain astrocytes is dependent on infarct presence and infarct age," Neuropathology, vol. 29, no. 2, pp. 125131, 2009.

[18] J. Waak, S. S. Weber, A. Waldenmaier et al., "Regulation of astrocyte inflammatory responses by the Parkinson's diseaseassociated gene DJ-1," The FASEB Journal, vol. 23, no. 8, pp. 2478-2489, 2009.

[19] S. J. Mullett and D. A. Hinkle, "DJ-1 deficiency in astrocytes selectively enhances mitochondrial Complex I inhibitorinduced neurotoxicity," Journal of Neurochemistry, vol. 117, no. 3, pp. 375-387, 2011.

[20] N. J. Larsen, G. Ambrosi, S. J. Mullett, S. B. Berman, and D. A. Hinkle, "DJ-1 knock-down impairs astrocyte mitochondrial function," Neuroscience, vol. 196, pp. 251-264, 2011.

[21] K. Takahashi, T. Taira, T. Niki, C. Seino, S. M. M. Iguchi-Ariga, and $\mathrm{H}$. Ariga, "DJ-1 positively regulates the androgen receptor by impairing the binding of PIASx alpha to the receptor," The Journal of Biological Chemistry, vol. 276, no. 40, pp. 3755637563, 2001.

[22] T. Niki, K. Takahashi-Niki, T. Taira, S. M. M. Iguchi-Ariga, and H. Ariga, "DJBP: a novel DJ-1-binding protein, negatively regulates the androgen receptor by recruiting histone deacetylase complex, and DJ-1 antagonizes this inhibition by abrogation of this complex," Molecular Cancer Research, vol. 1, no. 4, pp. 247261, 2003.

[23] Y. Shinbo, T. Taira, T. Niki, S. M. Iguchi-Ariga, and H. Ariga, "DJ-1 restores p53 transcription activity inhibited by Topors/p53BP3," International Journal of Oncology, vol. 26, no. 3, pp. 641-648, 2005.

[24] J. Xu, N. Zhong, H. Wang et al., “The Parkinson's diseaseassociated DJ-1 protein is a transcriptional co-activator that protects against neuronal apoptosis," Human Molecular Genetics, vol. 14, no. 9, pp. 1231-1241, 2005.

[25] N. Zhong, C. Y. Kim, P. Rizzu et al., "DJ-1 transcriptionally up-regulates the human tyrosine hydroxylase by inhibiting the sumoylation of pyrimidine tract-binding protein-associated splicing factor," The Journal of Biological Chemistry, vol. 281, no. 30, pp. 20940-20948, 2006.

[26] C. M. Clements, R. S. McNally, B. J. Conti, T. W. Mak, and J. P. Y. Ting, "DJ-1, a cancer- and Parkinson's diseaseassociated protein, stabilizes the antioxidant transcriptional master regulator Nrf2," Proceedings of the National Academy of Sciences of the United States of America, vol. 103, no. 41, pp. 15091-15096, 2006.

[27] J. E. Tillman, J. Yuan, G. Gu et al., "DJ-1 binds androgen receptor directly and mediates its activity in hormonally treated prostate cancer cells," Cancer Research, vol. 67, no. 10, pp. 4630-4637, 2007.

[28] J. Fan, H. Ren, E. Fei et al., "Sumoylation is critical for DJ-1 to repress p53 transcriptional activity," The FEBS Letters, vol. 582, no. 7, pp. 1151-1156, 2008.
[29] S. Ishikawa, T. Taira, K. Takahashi-Niki, T. Niki, H. Ariga, and S. M. M. Iguchi-Ariga, "Human DJ-1-specific transcriptional activation of tyrosine hydroxylase gene," The Journal of Biological Chemistry, vol. 285, no. 51, pp. 39718-39731, 2010.

[30] A. Mitsumoto, Y. Nakagawa, A. Takeuchi, K. Okawa, A. Iwamatsu, and Y. Takanezawa, "Oxidized forms of peroxiredoxins and DJ-1 on two-dimensional gels increased in response to sublethal levels of paraquat," Free Radical Research, vol. 35, no. 3, pp. 301-310, 2001.

[31] T. Yokota, K. Sugawara, K. Ito, R. Takahashi, H. Ariga, and H. Mizusawa, "Down regulation of DJ-1 enhances cell death by oxidative stress, ER stress, and proteasome inhibition," Biochemical and Biophysical Research Communications, vol. 312, no. 4, pp. 1342-1348, 2003.

[32] T. Taira, Y. Saito, T. Niki, S. M. M. Iguchi-Ariga, K. Takahashi, and $\mathrm{H}$. Ariga, "DJ-1 has a role in antioxidative stress to prevent cell death," The EMBO Reports, vol. 5, no. 2, pp. 213-218, 2004.

[33] R. M. Canet-Avilés, M. A. Wilson, D. W. Miller et al., "The Parkinson's disease DJ-1 is neuroprotective due to cysteinesulfinic acid-driven mitochondrial localization," Proceedings of the National Academy of Sciences of the United States of America, vol. 101, no. 24, pp. 9103-9108, 2004.

[34] T. Kinumi, J. Kimata, T. Taira, H. Ariga, and E. Niki, "Cysteine106 of DJ-1 is the most sensitive cysteine residue to hydrogen peroxide-mediated oxidation in vivo in human umbilical vein endothelial cells," Biochemical and Biophysical Research Communications, vol. 317, no. 3, pp. 722-728, 2004.

[35] C. Martinat, S. Shendelman, A. Jonason et al., "Sensitivity to oxidative stress in DJ-1-deficient dopamine neurons: an ESderived cell model of primary Parkinsonism," PLoS Biology, vol. 2, no. 11, article e327, 2004.

[36] M. Inden, T. Taira, Y. Kitamura et al., "PARK7 DJ-1 protects against degeneration of nigral dopaminergic neurons in Parkinson's disease rat model," Neurobiology of Disease, vol. 24, no. 1, pp. 144-158, 2006.

[37] S. Shendelman, A. Jonason, C. Martinat, T. Leete, and A. Abeliovich, "DJ-1 Is a redox-dependent molecular chaperone that inhibits $\alpha$-synuclein aggregate formation," PLoS Biology, vol. 2, no. 11, article e362, 2004.

[38] W. Zhou, M. Zhu, M. A. Wilson, G. A. Petsko, and A. L. Fink, "The oxidation state of DJ-1 regulates its chaperone activity toward $\alpha$-synuclein," Journal of Molecular Biology, vol. 356, no. 4, pp. 1036-1048, 2006.

[39] J. A. Olzmann, K. Brown, K. D. Wilkinson et al., "Familial Parkinson's disease-associated L166P mutation disrupts DJ-1 protein folding and function," The Journal of Biological Chemistry, vol. 279, no. 9, pp. 8506-8515, 2004.

[40] S. Koide-Yoshida, T. Niki, M. Ueda et al., "DJ-1 degrades transthyretin and an inactive form of DJ-1 is secreted in familial amyloidotic polyneuropathy," International Journal of Molecular Medicine, vol. 19, no. 6, pp. 885-893, 2007.

[41] J. Chen, L. Li, and L. S. Chin, "Parkinson disease protein DJ1 converts from a zymogen to a protease by carboxyl-terminal cleavage," Human Molecular Genetics, vol. 19, no. 12, pp. 23952408, 2010.

[42] H. Ooe, T. Taira, S. M. M. Iguchi-Ariga, and H. Ariga, "Induction of reactive oxygen species by bisphenol A and abrogation of bisphenol A-induced cell injury by DJ-1," Toxicological Sciences, vol. 88, no. 1, pp. 114-126, 2005.

[43] H. M. Li, T. Niki, T. Taira, S. M. M. Iguchi-Ariga, and H. Ariga, "Association of DJ-1 with chaperones and enhanced 
association and colocalization with mitochondrial Hsp70 by oxidative stress," Free Radical Research, vol. 39, no. 10, pp. 10911099, 2005.

[44] E. Junn, W. H. Jang, X. Zhao, B. S. Jeong, and M. M. Mouradian, "Mitochondrial localization of DJ-1 leads to enhanced neuroprotection," Journal of Neuroscience Research, vol. 87, no. 1, pp. 123-129, 2009.

[45] T. Hayashi, C. Ishimori, K. Takahashi-Niki et al., "DJ-1 binds to mitochondrial complex I and maintains its activity," Biochemical and Biophysical Research Communications, vol. 390, no. 3, pp. 667-672, 2009.

[46] I. Irrcher, H. Aleyasin, E. L. Seifert et al., "Loss of the Parkinson's disease-linked gene DJ-1 perturbs mitochondrial dynamics," Human Molecular Genetics, vol. 19, no. 19, pp. 3734-3746, 2010.

[47] L. Y. Hao, B. I. Giasson, and N. M. Bonini, "DJ-1 is critical for mitochondrial function and rescues PINK1 loss of function," Proceedings of the National Academy of Sciences of the United States of America, vol. 107, no. 21, pp. 9747-9752, 2010.

[48] G. Krebiehl, S. Ruckerbauer, L. F. Burbulla et al., "Reduced basal autophagy and impaired mitochondrial dynamics due to loss of Parkinson's disease-associated protein DJ-1," PLoS ONE, vol. 5, no. 2, Article ID e9367, 2010.

[49] H. Ren, K. Fu, D. Wang, C. Mu, and G. Wang, "Oxidized DJ-1 interacts with the mitochondrial protein BCL-XL," The Journal of Biological Chemistry, vol. 286, no. 40, pp. 35308-35317, 2011.

[50] K. J. Thomas, M. K. McCoy, J. Blackinton et al., "DJ-1 acts in parallel to the PINK1/parkin pathway to control mitochondrial function and autophagy," Human Molecular Genetics, vol. 20, no. 1, pp. 40-50, 2011.

[51] X. Wang, T. G. Petrie, Y. Liu, J. Liu, H. Fujioka, and X. Zhu, "Parkinson's disease-associated DJ-1 mutations impair mitochondrial dynamics and cause mitochondrial dysfunction," Journal of Neurochemistry, vol. 121, no. 5, pp. 830-839, 2012.

[52] J. Y. Heo, J. H. Park, S. J. Kim et al., "DJ-1 null dopaminergic neuronal cells exhibit defects in mitochondrial function and structure: involvement of mitochondrial complex I assembly," PLoS One, vol. 7, no. 3, article e32629, 2012.

[53] A. Wagenfeld, J. Gromoll, and T. G. Cooper, "Molecular cloning and expression of rat contraception associated protein 1 (CAP1), a protein putatively involved in fertilization," Biochemical and Biophysical Research Communications, vol. 251, no. 2, pp. 545549, 1998.

[54] J. E. Welch, R. R. Barbee, N. L. Roberts, J. D. Suarez, and G. R. Klinefelter, "Breakthrough in andrology: Sp22: a novel fertility protein from a highly conserved gene family," Journal of Andrology, vol. 19, no. 4, pp. 385-393, 1998.

[55] F. Le Naour, D. E. Misek, M. C. Krause et al., "Proteomics-based identification of RS/DJ-1 as a novel circulating tumor antigen in breast cancer," Clinical Cancer Research, vol. 7, no. 11, pp. 33283335, 2001.

[56] L. Allard, P. R. Burkhard, P. Lescuyer et al., "PARK7 and nucleoside diphosphate kinase A as plasma markers for the early diagnosis of stroke," Clinical Chemistry, vol. 51, no. 11, pp. $2043-$ 2051, 2005.

[57] M. Waragai, J. Wei, M. Fujita et al., "Increased level of DJ1 in the cerebrospinal fluids of sporadic Parkinson's disease," Biochemical and Biophysical Research Communications, vol. 345, no. 3, pp. 967-972, 2006.

[58] M. Waragai, M. Nakai, J. Wei et al., "Plasma levels of DJ-1 as a possible marker for progression of sporadic Parkinson's disease," Neuroscience Letters, vol. 425, no. 1, pp. 18-22, 2007.
[59] C. Maita, S. Tsuji, I. Yabe et al., "Secretion of DJ-1 into the serum of patients with Parkinson's disease," Neuroscience Letters, vol. 431, no. 1, pp. 86-89, 2008.

[60] Y. Tsuboi, H. Munemoto, S. Ishikawa, K. I. Matsumoto, S. M. M. Iguchi-Ariga, and H. Ariga, "DJ-1, a causative gene product of a familial form of Parkinson's disease, is secreted through microdomains," The FEBS Letters, vol. 582, no. 17, pp. 26432649, 2008.

[61] S. J. Kim, Y. J. Park, I. Y. Hwang, M. B. Youdim, K. S. Park, and Y. J. Oh, "Nuclear translocation of DJ-1 during oxidative stressinduced neuronal cell death," Free Radical Biology \& Medicine, vol. 53, no. 4, pp. 936-950, 2012.

[62] J. Choi, M. C. Sullards, J. A. Olzmann et al., "Oxidative damage of DJ-1 is linked to sporadic Parkinson and Alzheimer diseases," The Journal of Biological Chemistry, vol. 281, no. 16, pp. 1081610824, 2006.

[63] A. Mitsumoto and Y. Nakagawa, "DJ-1 is an indicator for endogenous reactive oxygen species elicited by endotoxin," Free Radical Research, vol. 35, no. 6, pp. 885-893, 2001.

[64] J. I. Lucas and I. Marín, "A new evolutionary paradigm for the Parkinson disease gene DJ-1," Molecular Biology and Evolution, vol. 24, no. 2, pp. 551-561, 2007.

[65] Y. Shinbo, T. Niki, T. Taira et al., "Proper SUMO-1 conjugation is essential to DJ-1 to exert its full activities," Cell Death and Differentiation, vol. 13, no. 1, pp. 96-108, 2006.

[66] G. Ito, H. Ariga, Y. Nakagawa, and T. Iwatsubo, "Roles of distinct cysteine residues in S-nitrosylation and dimerization of DJ-1," Biochemical and Biophysical Research Communications, vol. 339, no. 2, pp. 667-672, 2006.

[67] R. Rahman-Roblick, U. Hellman, S. Becker et al., "Proteomic identification of p53-dependent protein phosphorylation," Oncogene, vol. 27, no. 35, pp. 4854-4859, 2008.

[68] S. Yamaguchi, T. Yamane, K. Takahashi-Niki et al., "Transcriptional activation of low-density lipoprotein receptor gene by DJ1 and effect of DJ-1 on cholesterol homeostasis," PLoS One, vol. 7, no. 5, article e38144, 2012.

[69] J. Fan, H. Ren, N. Jia et al., "DJ-1 decreases Bax expression through repressing p53 transcriptional activity," The Journal of Biological Chemistry, vol. 283, no. 7, pp. 4022-4030, 2008.

[70] I. Kato, H. Maita, K. Takahashi-Niki et al., "Oxidized DJ-1 inhibits p53 by sequestering p53 from promoters in a DNAbinding affinity-dependent manner," Molecular and Cellular Biology, vol. 33, no. 2, pp. 340-359, 2013.

[71] H. Nishinaga, K. Takahashi-Niki, T. Taira, A. Andreadis, S. M. M. Iguchi-Ariga, and H. Ariga, "Expression profiles of genes in DJ-1-knockdown and L166P DJ-1 mutant cells," Neuroscience Letters, vol. 390, no. 1, pp. 54-59, 2005.

[72] W. Zhou and C. R. Freed, "DJ-1 up-regulates glutathione synthesis during oxidative stress and inhibits A53T $\alpha$-synuclein toxicity," The Journal of Biological Chemistry, vol. 280, no. 52, pp. 43150-43158, 2005.

[73] M. S. Goldberg, A. Pisani, M. Haburcak et al., "Nigrostriatal dopaminergic deficits and hypokinesia caused by inactivation of the familial parkinsonism-linked gene DJ-1," Neuron, vol. 45, no. 4, pp. 489-496, 2005.

[74] R. H. Kim, P. D. Smith, H. Aleyasin et al., "Hypersensitivity of DJ-1-deficient mice to 1-methyl-4-phenyl-1,2,3,6- tetrahydropyrindine (MPTP) and oxidative stress," Proceedings of the National Academy of Sciences of the United States of America, vol. 102, no. 14, pp. 5215-5220, 2005. 
[75] L. Chen, B. Cagniard, T. Mathews et al., "Age-dependent motor deficits and dopaminergic dysfunction in DJ-1 null mice," The Journal of Biological Chemistry, vol. 280, no. 22, pp. 21418-21426, 2005.

[76] S. Ishikawa, T. Taira, T. Niki et al., "Oxidative status of DJ-1dependent activation of dopamine synthesis through interaction of tyrosine hydroxylase and 4-dihydroxy-L-phenylalanine (L-DOPA) decarboxylase with DJ-1," The Journal of Biological Chemistry, vol. 284, no. 42, pp. 28832-28844, 2009.

[77] S. Ishikawa, Y. Tanaka, K. Takahashi-Niki, T. Niki, H. Ariga, and S. M. M. Iguchi-Ariga, "Stimulation of vesicular monoamine transporter 2 activity by DJ-1 in SH-SY5Y cells," Biochemical and Biophysical Research Communications, vol. 421, no. 4, pp. 813-818, 2012.

[78] F. Yotsumoto, A. Sanui, T. Fukami et al., "Efficacy of ligandbased targeting for the EGF system in cancer," Anticancer Research, vol. 29, no. 11, pp. 4879-4885, 2009.

[79] K. Takeuchi and F. Ito, "EGF receptor in relation to tumor development: molecular basis of responsiveness of cancer cells to EGFR-targeting tyrosine kinase inhibitors," FEBS Journal, vol. 277, no. 2, pp. 316-326, 2010.

[80] R. H. Kim, M. Peters, Y. Jang et al., "DJ-1, a novel regulator of the tumor suppressor PTEN," Cancer Cell, vol. 7, no. 3, pp. 263-273, 2005.

[81] Y. C. Kim, H. Kitaura, T. Taira, S. M. M. Iguchi-Ariga, and H. Ariga, "Oxidation of DJ-1-dependent cell transformation through direct binding of DJ-1 to PTEN," International Journal of Oncology, vol. 35, no. 6, pp. 1331-1341, 2009.

[82] B. Tang, H. Xiong, P. Sun et al., "Association of PINK1 and DJ-1 confers digenic inheritance of early-onset Parkinson's disease," Human Molecular Genetics, vol. 15, no. 11, pp. 1816-1825, 2006.

[83] K. Hattori, I. Naguro, C. Runchel, and H. Ichijo, "The roles of ASK family proteins in stress responses and diseases," Cell Communication and Signaling, vol. 7, article 9, 2009.

[84] S. Shiizaki, I. Naguro, and H. Ichijo, "Activation mechanisms of ASK1 in response to various stresses and its significance in intracellular signaling," Advances in Biological Regulation, vol. 53, no. 1, pp. 135-144, 2013.

[85] T. Iriyama, K. Takeda, H. Nakamura et al., "ASK1 and ASK2 differentially regulate the counteracting roles of apoptosis and inflammation in tumorigenesis," The EMBO Journal, vol. 28, no. 7, pp. 843-853, 2009.

[86] M. Benhar, D. Engelberg, and A. Levitzki, "ROS, stressactivated kinases and stress signaling in cancer," The EMBO Reports, vol. 3, no. 5, pp. 420-425, 2002.

[87] R. A. Thandavarayan, K. Watanabe, M. Ma et al., "14-3-3 protein regulates Ask1 signaling and protects against diabetic cardiomyopathy," Biochemical Pharmacology, vol. 75, no. 9, pp. 1797-1806, 2008.

[88] E. Yamamoto, Y. F. Dong, K. Kataoka et al., "Olmesartan prevents cardiovascular injury and hepatic steatosis in obesity and diabetes, accompanied by apoptosis signal regulating Kinase-1 inhibition," Hypertension, vol. 52, no. 3, pp. 573-580, 2008.

[89] Y. Izumiya, S. Kim, Y. Izumi et al., "Apoptosis signal-regulating kinase 1 plays a pivotal role in angiotensin II-induced cardiac hypertrophy and remodelling," Circulation Research, vol. 93, no. 9, pp. 874-883, 2003.

[90] O. Yamaguchi, Y. Higuchi, S. Hirotani et al., “Targeted deletion of apoptosis signal-regulating kinase 1 attenuates left ventricular remodeling," Proceedings of the National Academy of Sciences of the United States of America, vol. 100, no. 26, pp. 15883-15888, 2003.
[91] H. Nishitoh, A. Matsuzawa, K. Tobiume et al., "ASK1 is essential for endoplasmic reticulum stress-induced neuronal cell death triggered by expanded polyglutamine repeats," Genes \& Development, vol. 16, no. 11, pp. 1345-1355, 2002.

[92] H. Nishitoh, H. Kadowaki, A. Nagai et al., "ALS-linked mutant SOD1 induces ER stress- and ASK1-dependent motor neuron death by targeting Derlin-1," Genes \& Development, vol. 22, no. 11, pp. 1451-1464, 2008.

[93] H. Kadowaki, H. Nishitoh, F. Urano et al., "Amyloid $\beta$ induces neuronal cell death through ROS-mediated ASK1 activation," Cell Death and Differentiation, vol. 12, no. 1, pp. 19-24, 2005.

[94] P. M. Abou-Sleiman, D. G. Healy, N. Quinn, A. J. Lees, and N. W. Wood, "The role of pathogenic DJ-1 mutations in Parkinson's disease," Annals of Neurology, vol. 54, no. 3, pp. 283-286, 2003.

[95] R. Hering, K. M. Strauss, X. Tao et al., "Novel homozygous p.E64D mutation in DJ1 in early onset Parkinson disease (PARK7)," Human Mutation, vol. 24, no. 4, pp. 321-329, 2004.

[96] H. Aleyasin, M. W. C. Rousseaux, M. Phillips et al., “The Parkinson's disease gene DJ-1 is also a key regulator of strokeinduced damage," Proceedings of the National Academy of Sciences of the United States of America, vol. 104, no. 47, pp. 18748-18753, 2007.

[97] D. Yanagisawa, Y. Kitamura, M. Inden et al., "DJ-1 protects against neurodegeneration caused by focal cerebral ischemia and reperfusion in rats," Journal of Cerebral Blood Flow and Metabolism, vol. 28, no. 3, pp. 563-578, 2008.

[98] D. Malhotra, R. Thimmulappa, A. Navas-Acien et al., "Decline in NRF2-regulated antioxidants in chronic obstructive pulmonary disease lungs due to loss of its positive regulator, DJ-1," American Journal of Respiratory and Critical Care Medicine, vol. 178, no. 6, pp. 592-604, 2008.

[99] D. Jain, R. Jain, D. Eberhard et al., "Age- and diet-dependent requirement of DJ-1 for glucose homeostasis in mice with implications for human type 2 diabetes," Journal of Molecular Cell Biology, vol. 4, no. 4, pp. 221-230, 2012.

[100] E. Junn, H. Taniguchi, B. S. Jeong, X. Zhao, H. Ichijo, and M. M. Mouradian, "Interaction of DJ-1 with Daxx inhibits apoptosis signal-regulating kinase 1 activity and cell death," Proceedings of the National Academy of Sciences of the United States of America, vol. 102, no. 27, pp. 9691-9696, 2005.

[101] S. Karunakaran, L. Diwakar, U. Saeed et al., "Activation of apoptosis signal regulating kinase 1 (ASK1) and translocation of death-associated protein, Daxx, in substantia nigra pars compacta in a mouse model of Parkinson's disease: protection by $\alpha$-lipoic acid," The FASEB Journal, vol. 21, no. 9, pp. 22262236, 2007.

[102] J. Waak, S. S. Weber, K. Görner et al., "Oxidizable residues mediating protein stability and cytoprotective interaction of DJ-1 with apoptosis signal-regulating kinase 1," The Journal of Biological Chemistry, vol. 284, no. 21, pp. 14245-14257, 2009.

[103] N. Lev, D. Ickowicz, Y. Barhum, S. Lev, E. Melamed, and D. Offen, "DJ-1 protects against dopamine toxicity," Journal of Neural Transmission, vol. 116, no. 2, pp. 151-160, 2009.

[104] L. Aron, P. Klein, T. T. Pham, E. R. Kramer, W. Wurst, and R. Klein, "Pro-survival role for Parkinson's associated gene DJ-1 revealed in trophically impaired dopaminergic neurons," PLoS Biology, vol. 8, no. 4, article e1000349, 2010.

[105] H. Gao, W. Yang, Z. Qi et al., "DJ-1 protects dopaminergic neurons against rotenone-induced apoptosis by enhancing ERK-dependent mitophagy," Journal of Molecular Biology, vol. 423, no. 2, pp. 232-248, 2012. 
[106] Y. Mizuno, S. Ohta, M. Tanaka et al., "Deficiencies in complex I subunits of the respiratory chain in Parkinson's disease," Biochemical and Biophysical Research Communications, vol. 163, no. 3, pp. 1450-1455, 1989.

[107] W. D. Parker Jr., S. J. Boyson, and J. K. Parks, "Abnormalities of the electron transport chain in idiopathic Parkinson's disease," Annals of Neurology, vol. 26, no. 6, pp. 719-723, 1989.

[108] A. H. V. Schapira, J. M. Cooper, D. Dexter, J. B. Clark, P. Jenner, and C. D. Marsden, "Mitochondrial complex I deficiency in Parkinson's disease," Journal of Neurochemistry, vol. 54, no. 3, pp. 823-827, 1990.

[109] M. Orth and A. H. V. Schapira, "Mitochondrial involvement in Parkinson's disease," Neurochemistry International, vol. 40, no. 6, pp. 533-541, 2002.

[110] Y. Mizuno, H. Yoshino, S. I. Ikebe et al., "Mitochondrial dysfunction in Parkinson's disease," Annals of Neurology, vol. 44, no. 3, pp. S99-S109, 1998.

[111] E. Giaime, H. Yamaguchi, C. A. Gautier, T. Kitada, and J. Shen, "Loss of DJ-1 does not affect mitochondrial respiration but increases ROS production and mitochondrial permeability transition pore opening," PLoS One, vol. 7, no. 7, aricle e40501, 2012.

[112] L. Zhang, M. Shimoji, B. Thomas et al., "Mitochondrial localization of the Parkinson's disease related protein DJ-1: implications for pathogenesis," Human Molecular Genetics, vol. 14, no. 14, pp. 2063-2073, 2005.

[113] C. Maita, H. Maita, S. M. M. Iguchi-Ariga, and H. Ariga, "Monomer DJ-1 and its N-terminal sequence are necessary for mitochondrial localization of DJ-1 mutants," PLoS One, vol. 8, no. 1, article e54087, 2013.

[114] L. de Mena, E. Coto, E. Sánchez-Ferrero et al., "Mutational screening of the mortalin gene (HSPA9) in Parkinson's disease," Journal of Neural Transmission, vol. 116, no. 10, pp. 1289-1293, 2009.

[115] S. Miyazaki, T. Yanagida, K. Nunome et al., "DJ-1-binding compounds prevent oxidative stress-induced cell death and movement defect in Parkinson's disease model rats," Journal of Neurochemistry, vol. 105, no. 6, pp. 2418-2434, 2008.

[116] Y. Kitamura, S. Watanabe, M. Taguchi et al., "Neuroprotective effect of a new DJ-1-binding compound against neurodegeneration in Parkinson's disease and stroke model rats," Molecular Neurodegeneration, vol. 6, no. 1, article 48, 2011.

[117] M. Inden, Y. Kitamura, K. Takahashi et al., "Protection against dopaminergic neurodegeneration in Parkinson's disease-model animals by a modulator of the oxidized form of DJ-1, a wildtype of familial Parkinson's disease-linked PARK7," Journal of Pharmacological Sciences, vol. 117, no. 3, pp. 189-203, 2011. 


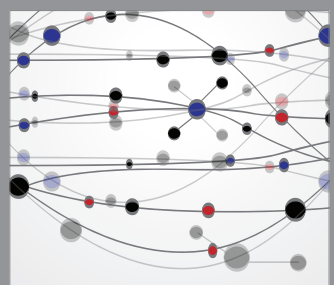

The Scientific World Journal
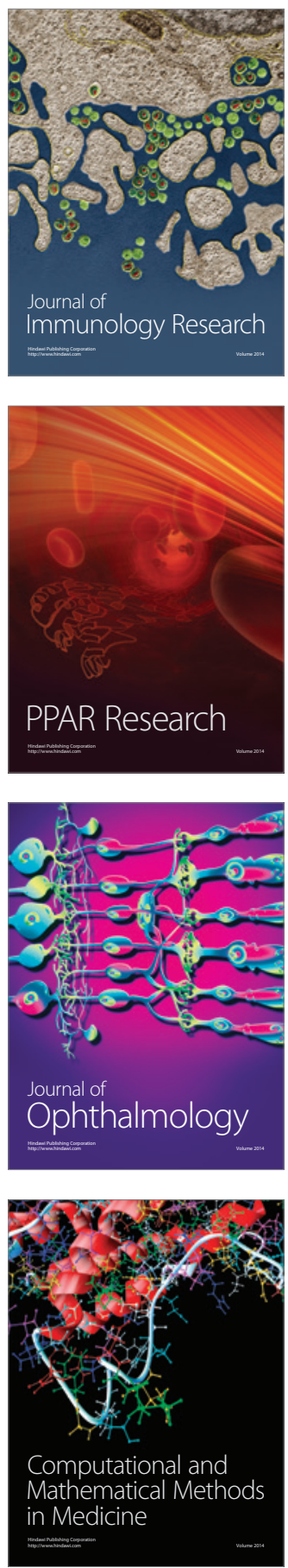

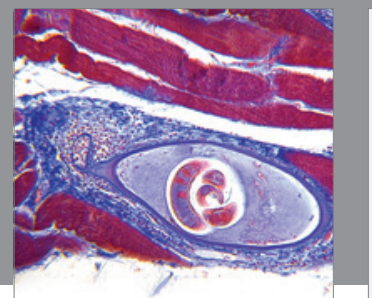

Gastroenterology

Research and Practice
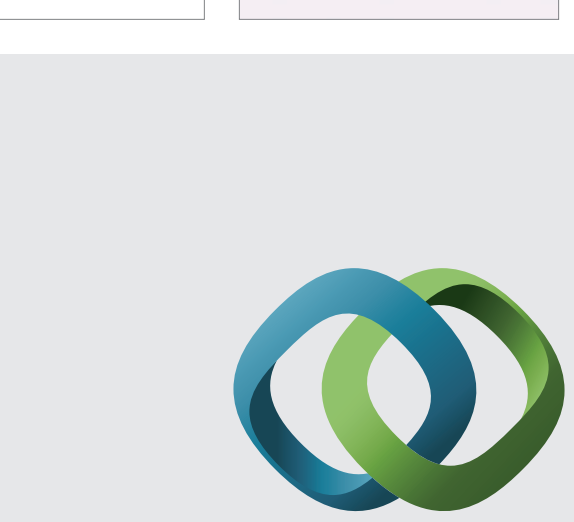

\section{Hindawi}

Submit your manuscripts at

http://www.hindawi.com
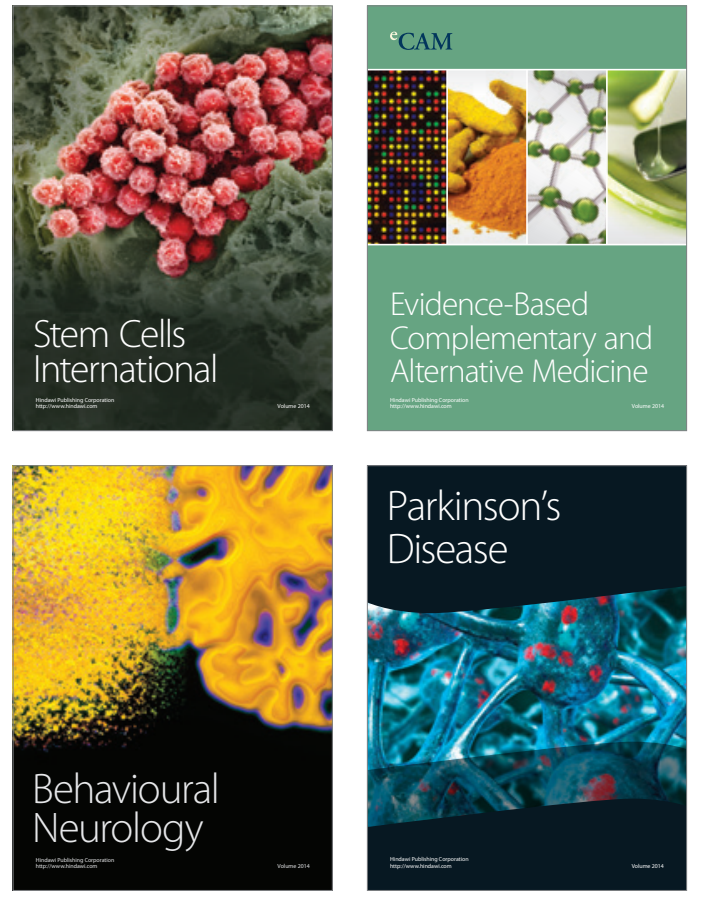
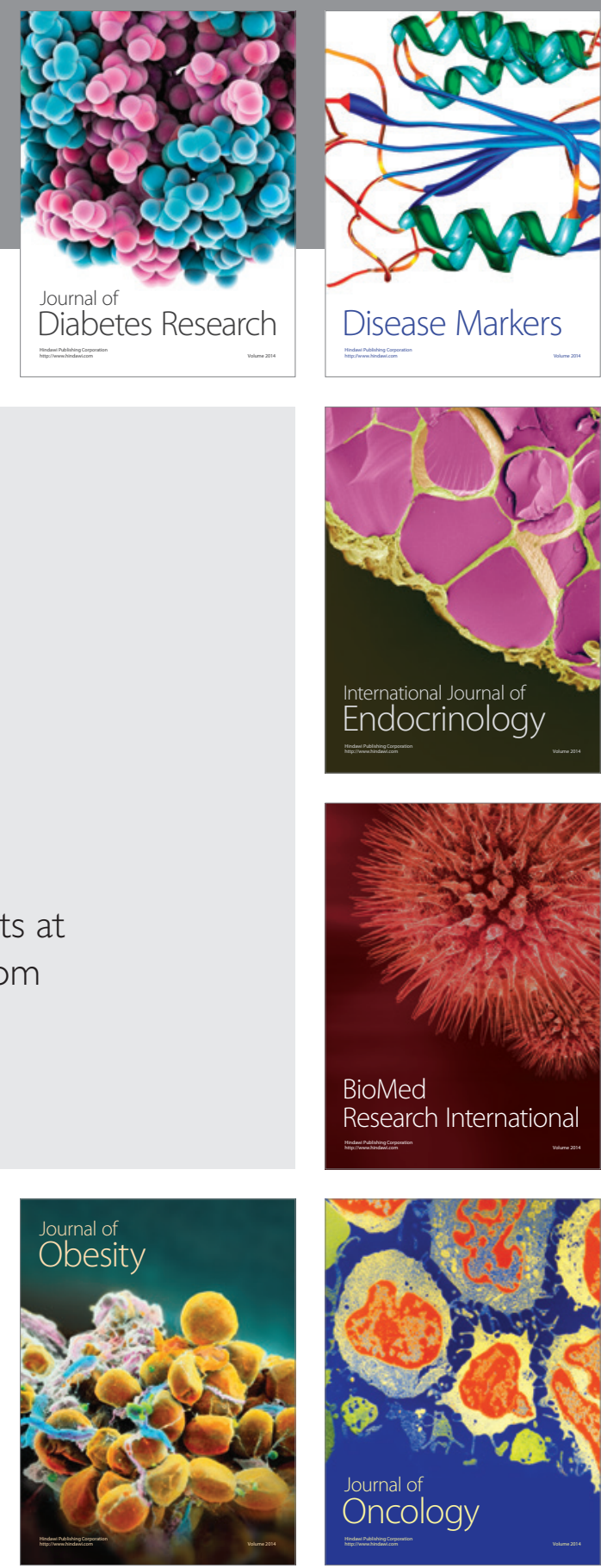

Disease Markers
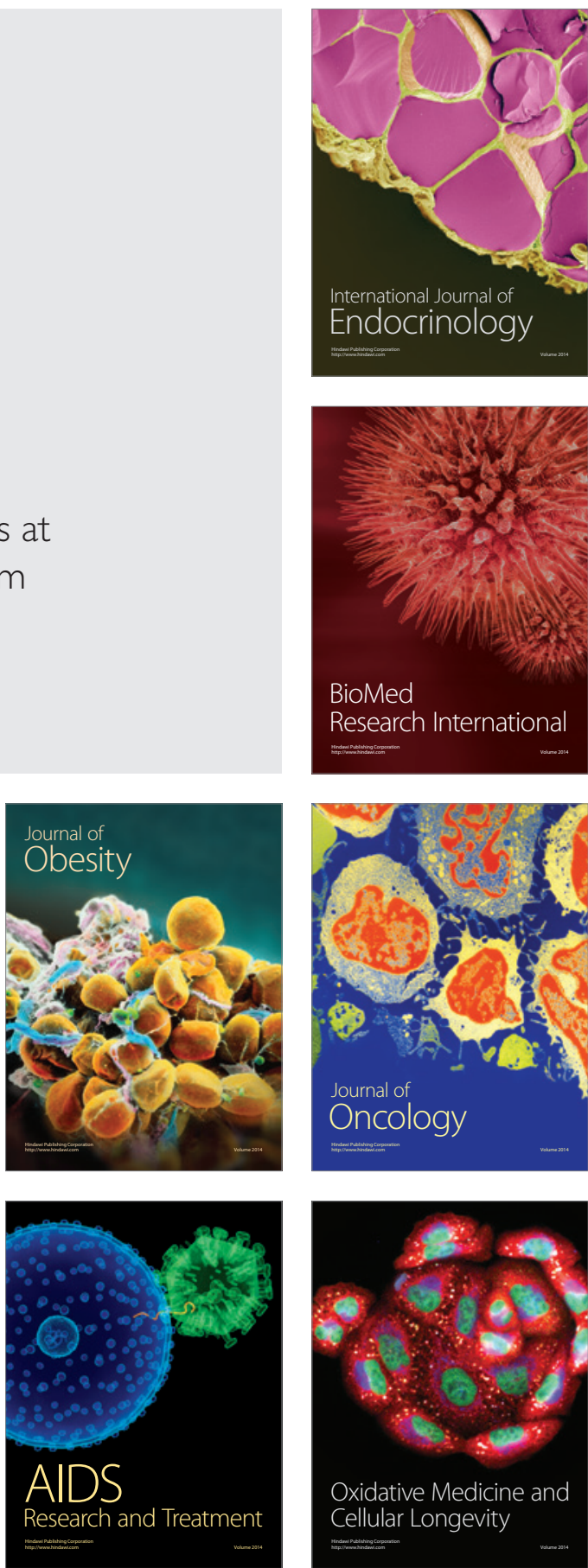